\title{
Exploring persuasion knowledge in food advertising: an empirical analysis
}

\author{
Svenja Mohr ${ }^{1}$ D $\cdot$ Rainer Kühl $^{1}$
}

Received: 7 January 2021 / Accepted: 23 June 2021 / Published online: 16 July 2021

(c) The Author(s) 2021

\begin{abstract}
Food purchase decisions are characterized by habitual purchase behavior and low consumer involvement. The main aim of food marketing is to influence food consumers, for example, through advertising. In order to illustrate the interaction between consumers and marketers, Friestad and Wright (1994) developed the Persuasion Knowledge Model. The Persuasion Knowledge Model postulates that consumers' dealing with persuasion attempts depends on three knowledge factors: persuasion, agent, and topic knowledge. In this paper, we apply the Persuasion Knowledge Model to food advertising. Based on an online survey with German students $(n=420)$, a structural equation analysis is used to investigate how persuasion knowledge determinants influence food consumers' avoidance of the persuasion attempt which is presented as a hypothetical but typical food advertisement. Results show that the dependent variable beliefs about consumers' avoidance of the persuasion attempt is negatively influenced by consumers' beliefs about psychological mediators in the advertisement and by consumers' beliefs about the appropriateness and effectiveness of the persuasion tactic. The determinant consumers' beliefs about persuasion coping goals and tactics positively influences consumers' avoidance of the persuasion attempt. From these findings, we derive recommendations for food industry advertisers and consumer education.
\end{abstract}

Keywords Persuasion knowledge $\cdot$ Structural equation model $\cdot$ Survey $\cdot$ Food advertising $\cdot$ Consumer behavior

JEL Classification L66 - Q18 · D12

Svenja Mohr

Svenja.Mohr@ernaehrung.uni-giessen.de

1 Institute of Agribusiness Management and Food Economics, Justus Liebig University Giessen,

Senckenbergstrasse 3, 35390 Giessen, Germany 


\section{Introduction}

Consumers are often not aware of food advertising and food purchase decisions are typically habitual. The cognitive effort required to make purchase decisions for food is low among consumers and usually a once learned purchase behavior persists. This is accompanied by a low tendency to use information and small financial risks of a failed food purchase. Decisions at the point of sale are made unconsciously and routinely. Therefore, food products are often classified as products of low involvement (Grunert 2006; Neumann 2009). Food marketing aims to persuade consumers about food products across all media (Ham et al. 2016). In Germany, the food industry is one of the largest advertisers of all industries and advertises its products on all available platforms (Gunter 2016). A comparison of the advertising expenditures of various food groups in Germany shows that the highest spending in 2017 was on sweets ( $€ 867.8$ million), followed by dairy products ( $€ 324.5$ million) (Nielsen and Media Impact 2018). Due to the low involvement of food consumers in purchase decisions, advertisers try to involve consumers in advertising messages through, e.g., emotional elements and to persuade them to buy their products (Neumann 2009). Advertisers aim to direct consumer preferences to the advertised product and to strengthen brand trust, in particular, for products which are bought habitually (Schweiger and Schrattenecker 2001).

The Persuasion Knowledge Model (PKM) by Friestad and Wright (1994) can be used to examine how consumers deal with advertising by illustrating the interaction between marketers and consumers during a persuasion episode. The underlying assumption of the PKM is that consumers try to maintain control over the persuasion attempt such as advertising messages or sales conversations by using persuasion, topic, and agent knowledge. According to Friestad and Wright (1994), the content and structure of persuasion knowledge are composed of the following five determinants: (1) beliefs about psychological mediators, (2) beliefs about marketers' tactics, (3) beliefs about one's own coping tactics, (4) beliefs about the effectiveness and appropriateness of marketers' tactics, (5) beliefs about marketers' persuasion goals and one's own coping goals. Friestad and Wright (1994, p. 3) indicate that "Consumers' persuasion coping knowledge enables them to recognize, analyze, interpret, evaluate, and remember persuasion attempts [...]". Consumers' topic knowledge is extracted from their product or service experience. Consumers' agent knowledge is derived from their expectations regarding the marketer's image, competencies, and company. Thus, on the consumers' side, the PKM can be used to gain detailed insights into consumer coping behavior. On the marketers' side, i.e. the advertisers, the PKM can provide insights on how to create and develop persuasion attempts to influence consumers' attitudes, decisions, and actions. To achieve this, persuasion, topic, and target knowledge are necessary (Friestad and Wright 1994; Kirmani and Campbell 2004).

The PKM can be applied to various research contexts (Friestad and Wright 1994). However, empirical research on persuasion knowledge and its determinants in food settings is rather rare although food purchase decisions differ from 
others, and advertising is highly important in the food industry. In the literature, there are experimental studies on persuasion in food advertising conducted with children (e.g., Naderer et al. 2020; Tarabashkina et al. 2016) and college students (Ham et al. 2016). Additionally, Eisend (2015) investigates the role of persuasion knowledge in third-party perceptions in a food advertising setting. However, in PKM studies only one or two factors of the PKM are investigated which indicates that the multidimensionality of the PKM and the various persuasion knowledge determinants are not sufficiently examined. To the best of our knowledge, there are no empirical studies that simultaneously examine multiple determinants of persuasion knowledge in a food advertising setting.

In this study, we investigate whether and to what extent the different persuasion knowledge determinants influence the beliefs about consumers' avoidance of a food advertising message using an online survey with 420 students. We develop contextspecific measurement scales for every determinant of persuasion knowledge. Due to the high advertising expenditures for sweets in Germany and because sweets are often bought habitually and impulsively, we develop an online advertisement for a fictitious chocolate bar as persuasion attempt. To examine the modeled relationships, we use structural equation modeling since structural equation models allow to measure hypothetical constructs, i.e., latent variables that are not directly observable like, e.g., attitudes or beliefs towards an advertising message. The aim of our study is to gain a deeper understanding of persuasion in food advertising focusing on multiple determinants of persuasion knowledge simultaneously.

Our results show that the determinants consumers' beliefs about psychological mediators in the advertisement and consumers' beliefs about the appropriateness of the persuasion tactic as well as consumers' beliefs about the effectiveness of the persuasion tactic have the largest and a statistically significant negative influence on the avoidance of the persuasion attempt. Beliefs about consumers' persuasion coping goals and tactics positively influence the avoidance of the persuasion attempt. In our study, $21.8 \%$ of the variance of advertisement avoidance can be explained by the factors investigated.

Since Friestad and Wright (1994, p. 25) mentioned that "The questions the PKM raises must be addressed by empirical studies using a variety of methods [...]", our paper contributes with its empirical analysis to the literature on persuasion research by exploring the effects of multiple persuasion knowledge determinants on food advertising avoidance. Our research approach shows how the persuasion knowledge determinants can be integrated into one framework and how their relevance for consumers' interaction with food advertising can be investigated. Ham et al. (2015) indicate that research on coping behavior with persuasion attempts is relevant for companies and consumers as well as for experts, the public, and consumer protection. In line with this, we conclude that the results of our study are of importance for advertisers in the food industry and for consumer education as they provide insights into the design of advertising and consumer protection, e.g., with regard to media use.

This paper is structured as follows: The following section explains the PKM in general and highlights its complexity and conceptual difficulties. We explain the determinants of persuasion knowledge and develop hypotheses. This is followed by 
the methodology section that includes information on the data collection and participants, the procedure and survey design, and the measures of our study. After verifying the quality criteria of the analysis and presenting the results in the fourth section, recommendations for food advertisers and consumer education are presented in the fifth section. The last section contains our conclusion, points to limitations, and provides a short outlook for future research.

\section{Theoretical background and hypotheses}

Friestad and Wright (1994) develop the PKM to explain the marketers' conception of and the consumers' coping with persuasion attempts like, e.g., advertising messages or sales conversations. Thus, the PKM is a framework which addresses both parties of persuasion interactions (see Fig. 1). Marketers, i.e. agents, create and develop persuasion attempts based on the three factors of topic, persuasion, and target knowledge to affect consumers' attitudes, decisions, and actions. For consumers, i.e. targets, the PKM provides insights about their coping behavior as they can use their topic, persuasion, and agent knowledge to deal with persuasion attempts. As Fig. 1 shows, during a persuasion episode the marketers with their persuasion attempts and the consumers with their coping behaviors come together (Friestad and Wright 1994; Ham et al. 2015; Kirmani and Campbell 2004).

On the occasion of the twentieth anniversary of the PKM, Ham et al. (2015) generate a review of research articles of the PKM published between 1994 and 2014. The review article discusses the methods and measuring instruments of 89 selected articles. In addition to the broad application possibilities of the PKM, the review article shows that there is no standard instrument for measuring the PKM factors and the respective determinants. Instead, researchers develop various measurement scales corresponding to the respective research object. The dominant methods identified are experiments and surveys. Furthermore, Ham et al. (2015) show that the majority of studies only examine some factors of the PKM or rather a few

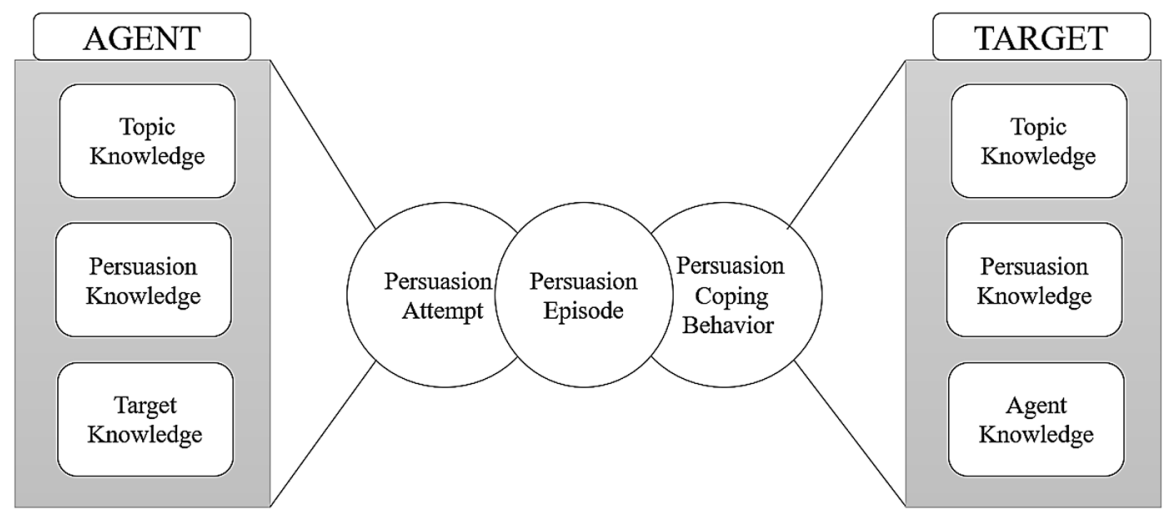

Fig. 1 The Persuasion Knowledge Model according to Friestad and Wright (1994) 
determinants of persuasion knowledge. Thus, the multidimensionality of the PKM remains rather unconsidered. In most studies, only one or two factors of the PKM are used, predominantly the persuasion knowledge factor, which is measured in different ways. However, focusing on persuasion knowledge is in accordance with the intention of Friestad and Wright (1994) who state that persuasion knowledge is the most important factor for coping with persuasion attempts. In various studies, differences in the measurement of persuasion knowledge can be observed. For example, Boerman et al. (2018) develop a persuasion knowledge scale for sponsored content that uses nine multi-item determinants, such as recognition, understanding, and appropriateness of sponsored and persuasive content. In contrast, Matthes and Naderer (2016) assess the activation of persuasion knowledge as one determinant with five indicators in the context of brand-unspecific product placement disclosures in music videos. The activation of persuasion knowledge is captured using items that measure respondents' awareness of a purposeful integration of product placements into the video. Persuasion knowledge in online behavioral advertising is evaluated as one determinant with six indicators that focuses on respondents' own knowledge of persuasive intentions of online advertising and marketers (Ham 2017). Bearden et al. (2001) use a factor analysis to develop a six-item measurement scale for persuasion knowledge as a dimension of consumer self-confidence. However, as mentioned above, Friestad and Wright (1994) indicate in their initial PKM paper that persuasion knowledge is composed of five determinants that lead consumers' coping behavior when dealing with a persuasion attempt.

The aim of our study is to investigate the multidimensionality of persuasion knowledge and we therefore simultaneously focus on five determinants. Ham et al. (2015) show in their literature review that various determinants of persuasion knowledge have been examined but there is no single scale to capture persuasion knowledge with all its determinants. In addition, they add that "the multidimensional nature of the model 'persuasion knowledge' has meant, largely, that researchers must develop their own scales, which fit the particular research context or "persuasion episode." (Ham et al. 2015, p. 19). Since there is not one scale for every individual determinant, we capture previously unmeasured constructs with statement mentioned in the original paper by Friestad and Wright (1994). Pretests show that this approach, however, leads to model-theoretical and content-related coincidences between Friestad and Wright's (1994) fifth determinant (beliefs about marketers' persuasion goals and one's own coping goals) and their second (beliefs about marketers' tactics) and third (beliefs about one's own coping tactics) determinants. In our study, we refrain from presenting and investigating Friestad and Wright's (1994) fifth determinant since pretests show that the survey is more understandable if we integrate the fifth determinant from Friestad and Wright (1994) into the second and third determinant. Therefore, we integrate the goals and tactics together in one determinant meaning that the marketers' (consumers') goals from Friestad and Wright's (1994) fifth determinant are measured within our second (third) determinant. Furthermore, we divide Friestad and Wright's (1994) fourth determinant (beliefs about the effectiveness and appropriateness of marketers' tactics) into two separate determinants (see in the following (4) and (5)). The rationale for measuring both factors separately is that, to our 
knowledge, no scale measures the beliefs about the effectiveness and appropriateness together. Instead, the review article by Ham et al. (2015) shows independent scales for measuring appropriateness (see Wei et al. 2008) and effectiveness (see Celsi and Gilly 2009), which justifies our approach. To integrate these scales and to address the coincidences mentioned above, we decide to slightly modify Friestad and Wright's (1994) persuasion knowledge determinants, and to investigate the following determinants:

(1) Consumers' beliefs about psychological mediators

(2) Consumers' beliefs about marketers' persuasion goals and tactics

(3) Consumers' beliefs about persuasion coping goals and tactics

(4) Consumers' beliefs about the appropriateness of the marketers' persuasion tactic

(5) Consumers' beliefs about the effectiveness of the marketers' persuasion tactic

Friestad and Wright (1994) mention that consumers' primary goal of coping with persuasion attempts is to maintain control over the outcome of a persuasion attempt. The authors use the term cope as it "is neutral with respect to the direction of targets' responses" (Friestad and Wright 1994, p. 3). Thus, maintaining control over a persuasion attempt means that consumers can use their persuasion knowledge to avoid (mistrust or disbelief) or to tolerate (trust or belief) persuasion attempts. A wide range of studies addresses the question of avoidance and shows that persuasion knowledge leads consumers to resist persuasion attempts such as advertising messages (e.g., Ahluwalia and Burnkrant 2004; Campbell and Kirmani 2000; Forehand and Grier 2003). In addition, the results of the survey by Ham et al. (2016) on online behavioral advertising show that consumers' coping behavior of advertising avoidance is connected with persuasion knowledge. Therefore, consumers do not believe in marketers' claims (Darke et al. 2008), or motives (Boush et al. 1994; Forehand and Grier 2003) which is described by Isaac and Grayson (2017) as consumers' skepticism. However, a positive handling of persuasion attempts means that persuasion knowledge leads, for example, to greater credibility such as trust about persuasion attempts. In line with this, Isaac and Grayson (2017) investigate if persuasion knowledge can sometimes lead to positive effects towards a persuasion attempt. Using four studies, the authors indicate that accessing persuasion knowledge by consumers can lead to greater credibility and that consumers perceive credible advertising tactics as beneficial. In their online experiment, Matthes and Naderer (2016) also point out that persuasion knowledge does not always lead to a more negative brand attitude.

Since the literature captures the resistance to a persuasion attempt as the main intention, we define the avoidance of the persuasion attempt as the dependent variable in our study. This is justified by the fact that consumers do not change their behavior or attitudes in favor of the advertised product (Fransen et al. 2015). Thus, consumers are likely to withdraw or even turn entirely away from the advertiser or brand which can range from a change in purchase behavior to a complete avoidance of a product purchase (Campbell and Kirmani 2008). Verlegh et al. (2015) mention that the avoidance of a persuasion attempt can be expressed, 
e.g., by changing the television channel in advertising blocks or by installing an advertising blocker for surfing on the internet. In a representative population survey conducted in Germany in 2018, the company PricewaterhouseCoopers (PwC) finds that $52 \%$ of the participants hide online advertising, at least partially, by using an advertising blocker (PwC 2019).

In the following, we introduce the determinants of persuasion knowledge in more detail and develop hypotheses. To avoid response bias, we do not ask respondents about their own expectations on each persuasion knowledge determinant but about their perceptions of consumers' beliefs about the respective determinant. Thus, we focus on the respondents' perception of consumers' beliefs of each persuasion knowledge determinant rather than on their own knowledge.

\section{(1) Consumers' beliefs about psychological mediators}

The first determinant of persuasion knowledge is consumers' beliefs about psychological mediators in the advertisement. This factor is perceived as the basis of persuasion knowledge and describes a certain perception, namely that psychological responses such as feelings, wishes, interests, or emotions are transmitted in persuasion attempts (Friestad and Wright 1994). Friestad and Wright (1995) examine the influence of television advertising on the audience and identify 13 psychological mediators, such as the arousal of emotions, or the development of trust caused by advertising.

For measuring consumers' beliefs about psychological mediators, we refer to the 13 psychological mediators mentioned by Friestad and Wright (1994). The later verification of the quality criteria in the results section shows that we retain seven of these indicators in our analysis. Thus, aspects, such as feelings, desires, interests, and emotions that can be perceived by our persuasion attempt are captured (see Appendix, Table 3). We assume that a positive evaluation of consumers' beliefs about psychological mediators in our advertising leads to a lower resistance to the advertisement among consumers. Therefore, we expect a negative effect on the advertisement avoidance. The first hypothesis is:

H1: Consumers' beliefs about psychological mediators in the advertisement negatively influence the avoidance of the persuasion attempt.

As the determinant consumers' beliefs about psychological mediators is described as the basis of persuasion knowledge, we assume that the other four determinants of persuasion knowledge are positively affected (Friestad and Wright 1994). Therefore, the following hypotheses are:

H1a: Consumers' beliefs about psychological mediators in the advertisement positively influence consumers' beliefs about marketers' persuasion goals and tactics.

H1b: Consumers' beliefs about psychological mediators in the advertisement positively influence consumers' beliefs about persuasion coping goals and tactics.

H1c: Consumers' beliefs about psychological mediators in the advertisement positively influence consumers' beliefs about the appropriateness of the marketers' persuasion tactic. 
H1d: Consumers' beliefs about psychological mediators in the advertisement positively influence consumers' beliefs about the effectiveness of the marketers' persuasion tactic.

\section{(2) Consumers' beliefs about marketers' persuasion goals and tactics}

The second determinant of persuasion knowledge is consumers' beliefs about marketers' persuasion goals and tactics that measures consumers' perception of how persuasion tactics can affect them (Friestad and Wright 1994; Ham et al. 2015). Persuasion tactics use psychological mediators and can range from attention-getting, scare, and curiosity to the enthusiasm of people for the product and can include, e.g., holistic message themes and specific messages (Friestad and Wright 1994). According to Friestad and Wright (1994, p. 4) "Persuasion tactics are therefore perceived as 'agent action-psychological event' connections". Boush et al. (1994) capture the knowledge about persuasion tactics with adolescents in the context of television advertising. Several questions are asked about tactics in combination with psychological effects of persuasion, such as the use of cartoon characteristics or popular music stars in television advertisements. Xie and Johnson (2015) use a six-item measurement scale developed by Bearden et al. (2001), which is limited to the knowledge about marketers' persuasion tactics, to determine the role of persuasion knowledge in the third-person effect ${ }^{1}$ (see Davison 1983). Their results show that consumers with a high level of persuasion knowledge assume that advertising tactics have a stronger effect on others than on themselves. These consumers are also convinced that they are more likely to identify inappropriate advertising tactics compared to consumers with a lower level of persuasion knowledge (Xie and Johnson 2015). In a study on third-party perceptions, Eisend (2015) uses a determinant called "knowledge about persuasion tactics and processes" to measure the entire construct of persuasion knowledge.

This short review shows that in some studies the determinant consumers' beliefs about marketers' persuasion goals and tactics is used to measure the entire construct of persuasion knowledge. Since we aim to capture multiple determinants of persuasion knowledge, we refer to the theoretical foundations of advertising effects to measure consumers' knowledge about marketers' persuasion goals and tactics. According to Felser (2015), advertisements present famous people to highlight product characteristics. Furthermore, scientific evidence can be used to establish the superiority of the advertised product, and images are presented as they are better memorized than words. Based on these advertising characteristics, we develop a general multi-item scale of marketers' persuasion goals and tactics to measure the second determinant (see Appendix, Table 3). We ask the participants about their perceptions of how general advertising goals and tactics of marketers can affect consumers. Friestad and Wright (1994) mention that a persuasion tactic is only noticed if the perceived characteristic of a persuasion attempt is causally related to

\footnotetext{
1 The third-person effect describes that people prefer to believe that the mass media influence others more than themselves (Davison 1983).
} 
a psychological mediator. This is why we include causal connections between the tactics and psychological mediators in our measurement scale. To derive the hypothesis, we refer to Eisend (2015, p. 59) who points out that "the more consumers believe they know about marketers' persuasive tactics, the more they believe they know how to behave in markets efficiently and how to control negative influences by advertising." In line with this quote, the following hypothesis is:

H2: Consumers' beliefs about marketers' persuasion goals and tactics positively influence the avoidance of the persuasion attempt.

\section{(3) Consumers' beliefs about persuasion coping goals and tactics}

The third determinant of persuasion knowledge is consumers' beliefs about persuasion coping goals and tactics. Consumers' persuasion coping skills result from their own persuasion goals, such as self-control and competency regarding persuasion tactics, their coping tactics, and their perceptions of how other consumers can cope with persuasion attempts (Friestad and Wright 1994; Ham et al. 2015). The initiators of the PKM discuss a range of tactical ways on how to cope with persuasion attempts, such as ignoring a persuasion attempt or establishing a long-term attitude towards the advertiser (Friestad and Wright 1994). Thus, consumers' persuasion coping goals and tactics are related to consumers' self-confidence in their ability to understand and to deal with advertising tactics (Bearden et al. 2001).

In our survey, we measure consumers' beliefs about persuasion coping goals and tactics in terms of consumers' self-confidence using items from the initial PKM article by Friestad and Wright (1994) (see Appendix, Table 3). According to the literature discussed above, we assume that a positive evaluation of consumers' beliefs about persuasion coping goals and tactics results in advertisement avoidance among consumers. Therefore, the third hypothesis is.

H3:Consumers' beliefs about persuasion coping goals and tactics positively influence the avoidance of the persuasion attempt.

(4) Consumers' beliefs about the appropriateness of the marketers' persuasion tactic

The fourth determinant of persuasion knowledge is consumers' beliefs about the appropriateness of the marketers' persuasion tactic. The appropriateness of persuasion tactics is an important subject in advertising research (West et al. 2019) and according to the PKM theory refers to whether the tactic is morally acceptable for consumers. In an experimental study, Wei et al. (2008) examine the perceived appropriateness of covert marketing tactics with undergraduate students. Therefore, various college radio shows are produced and the appropriateness of product placements in radio advertising is measured. The authors capture the perception of appropriateness based on the perceived fairness and the perceived acceptance of the respective tactic. The appropriateness of a persuasion tactic is also examined by Yoo (2009) as the perceived fairness of search engine ads using three items on appropriateness, payment, and acceptance which are adopted from Campbell's (1995) study of attention-getting tactics in television 
advertising. Results show that the perception of an appropriate advertisement in the search engine mitigates the negative effect of persuasion knowledge on clickthrough rates of keyword advertisements.

In our study, we examine the determinant consumers' beliefs about the appropriateness of the marketers' persuasion tactic by referring to the measurement scale of Wei et al. (2008). We modify the indicators about appropriateness and fairness according to the persuasion tactic used in our study (see Appendix, Table 3). In line with related studies (Ham et al. 2015; Wei et al. 2008), we expect that if a perceived persuasion tactic seems appropriate among consumers, the persuasion attempt is evaluated positively. Consequently, a persuasion tactic that is evaluated positively and, therefore, considered as appropriate does not lead to advertisement avoidance among consumers. Therefore, hypothesis $\mathrm{H} 4$ is:

H4: Consumers' beliefs about the appropriateness of the marketers' persuasion tactic negatively influence the avoidance of the persuasion attempt.

(5) Consumers' beliefs about the effectiveness of the marketers' persuasion tactic

The fifth determinant of persuasion knowledge is consumers' beliefs about the effectiveness of the marketers' persuasion tactics which depends on whether advertisers make use of psychological mediators in their persuasion attempts to influence purchase decisions (Friestad and Wright 1994). In their review article, Ham et al. (2015) point out that perceptions of advertising effectiveness are not frequently measured and refer to the study by Celsi and Gilly (2009) to capture this determinant.

In line with this recommendation, we refer to the study by Celsi and Gilly (2009) to measure the determinant beliefs about the effectiveness of the persuasion tactic, and transfer their measurement scale to our online food advertising setting (see Appendix, Table 3). Celsi and Gilly (2009) examine how employees evaluate the effectiveness of their company's advertising messages. The authors find out that if employees feel that the company's own advertising messages are effective and in line with their expectations, employees feel connected to their company and the respective advertising message. The persuasion attempt is therefore not avoided but rather tolerated. We follow this line of thought and conclude that the belief and perception about effective elements in an advertising tactic lead to an easier evaluation of the tactic which does not necessarily imply a rejection of the persuasion attempt. Beliefs about an effective advertising tactic can, therefore, result in a positive evaluation of the persuasion attempt. Therefore, hypothesis $\mathrm{H} 5$ is:

H5: Consumers' beliefs about the effectiveness of the marketers' persuasion tactic negatively influence the avoidance of the persuasion attempt.

Since we test our hypotheses with a student-based sample and do not expect considerable age variation, we deliberately refrain from formulating a hypothesis on the influence of age on our persuasion knowledge determinants. However, a substantial body of research on persuasion knowledge focuses on the relationship between persuasion knowledge and age (e.g., Balzás et al. 2017; Boush et al. 
1994; Waiguny et al. 2014). These scholars find that a better persuasion knowledge exists more likely among older than younger consumers since with growing age, consumers have more shopping experiences and more frequent as well as important purchase decisions are made. In addition, the ability to draw conclusions from marketers' characteristics increases since with increasing age, experiences with marketers are perceived more consciously, and persuasion attempts are questioned and recognized more frequently (Friestad and Wright 1994). However, consumers' knowledge of a persuasion attempt decreases again at a certain age (Kirmani and Campbell 2004). Especially elderly people are considered to be vulnerable as skills to ensure well-being in persuasive situations diminish and difficulties arise in maintaining their own interests (Valant 2015).

\section{Methodology}

\section{Data collection and participants}

To test our hypotheses, we created an online survey with the software LimeSurvey. Our survey was conducted in 2018 and 2019 and participants were students of the University of Giessen, Germany. The survey link was sent via the IT service center to all students of the university which means that in each of the 2 years approximately 28,000 people received the survey link. In both years, the link was online for a total of 20 days. We encouraged participation in the online survey by a random draw of ten chocolate bar surprise packages valued at 10 euros respectively. In 2018, 300 respondents and in 2019, 317 respondents participated in our survey. The drop-out rate was $31.93 \%(n=197)$ and thus a total of $68.07 \%(n=420)$ of the participants completed our survey. Participants' age ranged from 18 to 57 years and the average age was 24.23 years $(s d=4.74)$. The share of female participants was $77.62 \%(n=326)$. In total, $42.86 \%(n=180)$ of the respondents stated that they deal with nutrition issues in their university studies which indicated that they were studying nutritional science or related studies with lectures on nutrition and food.

\section{Procedure and survey design}

Before our survey was submitted to the students, we conducted two pre-test rounds. In the first pre-test round, we tested all indicators with five external students to ensure that all indicators were understandable and unambiguous. In a second pretest with five doctoral students, the entire online survey was checked for response time and for further linguistic and content improvements. As a result, we rephrased some indicators and optimized the advertisement of the chocolate bar. Our survey consisted of three stages, which are presented in Fig. 2.

In the beginning, we announced our study as survey about food advertising. We presented a short introduction to invite and inform participants about the estimated 


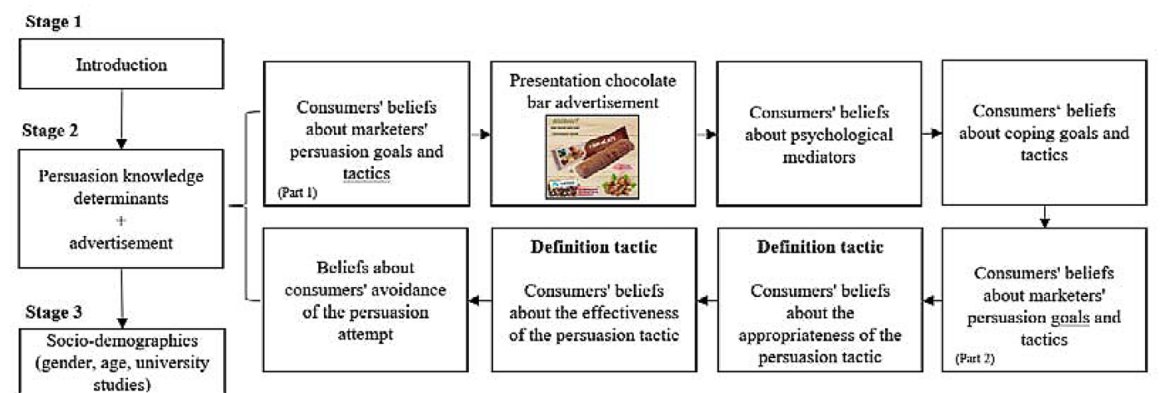

Fig. 2 Survey structure

time required and data protection issues. In addition, we informed respondents that there are no right or wrong answers and that all information provided is handled confidentially. In the second stage, we aimed to capture the constructs of persuasion knowledge by using multi-item scales and presented the advertisement of the chocolate bar. First, we asked about the indicators of the second determinant consumers' beliefs about marketers' persuasion goals and tactics. Since we asked indicators [GT1] and [GT2] (see Appendix, Table 3) as general perceptions of advertising tactics and thus independently from our advertisement, these two indicators which focused on marketers' persuasion tactics were presented at first. As a second part of the determinant, the indicators on marketers' persuasion goals [GT3] (R) and [GT4] were queried at a later step (see Fig. 2). The indicators of the remaining determinants were directly related to the food advertisement and therefore presented after the illustration of the persuasion attempt. Since the persuasion attempt was an important stimulus for our survey and we developed a fictitious advertisement of a chocolate bar, we provide a more detailed explanation of its conception in the following.

Since our study focused on food advertising, we chose a chocolate bar as it is assumed to be a low involvement product that is purchased both habitually and impulsively due to the low financial risks and the product's substitutability. Due to these reasons and because of the high advertising expenditures of the sweets industry explained above, we regarded a chocolate bar to be a very suitable product for our analysis. Furthermore, we presented the commercial message in our survey as an online advertisement since the second highest advertising spending of the food industry is on online advertising (Nielsen 2013). Moreover, online advertising is an increasingly important advertising medium for advertisers and consumers. In recent years, especially target group-specific online advertising is gaining relevance. Advertisers use, for example, algorithms and artificial intelligence to transmit personalized information to consumers and place advertising media in line with their current purchase decision phase, their interests, and their preferences. Consumers receive personalized recommendations targeted in terms of time and topic that can be used for their purchase decisions (Acquisti et al. 2016; Li 2019). In line with this, Berkovsky et al. (2012) mentioned that personalized recommendations combined with persuasive contents could change consumer behavior. Kaptein et al. (2012), for 
example, investigated how personalized persuasive text messages can change study participants' eating habits to reduce snacking.

In our study, we developed the advertisement of the chocolate bar based on the involvement theory in food marketing (Neumann 2009). Neumann (2009) states that a food advertisement should have an activating and emotionalizing effect, create a positive image, and be linked to a more strongly involving element to draw consumers' attention to it. To comply with these recommendations, we integrated the two aspects care and hedonism into the advertisement of the chocolate bar (see Fig. 3). The care aspect intended to evoke care motives such as affection or attachment among consumers. The statement "Do something good for [...] the cocoa farmers!" was supposed to stimulate the care motive. The hedonism aspect intended to address consumer motives such as individual enjoyment or self-pampering and was initiated by the statements "Do something good for yourself" as well as by the two slogans "Chocolate taste" and "Extra high share of nuts" representing self-cherishing and individual taste. Pictures of cocoa beans and hazelnuts supported these statements. In our study, the more strongly involving element was the Fair-Trade label, which we also defined as the persuasion tactic. In a short text (see below), we described that the marketer actually aims to increase the sales figures, i.e., the company's revenue, and the marketer's primary goal is not the support of the cocoa farmers, which one would actually expect by using the Fair-Trade label. Since previous studies on advertising and persuasion knowledge used fictitious brands and marketers to avoid influences of previous associations with products, brands or the perceived corporate reputation (Darke et al. 2008; Held et al. 2017), we adapted this procedure and used a fictitious brand called "GOODNUT" without mentioning any marketer (see Fig. 3).

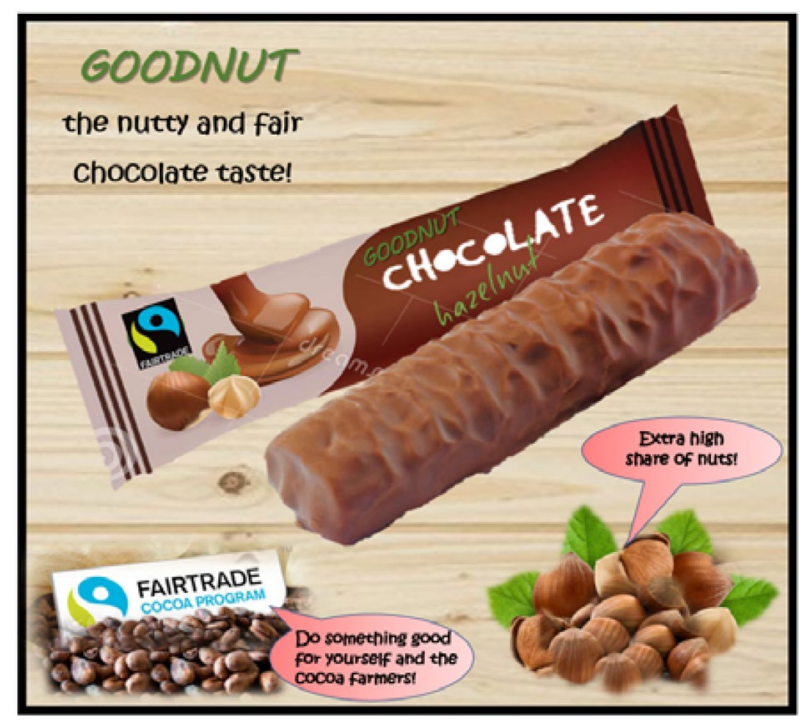

Fig. 3 Fictitious online advertisement of the chocolate bar "GOODNUT" 
After presenting the fictitious advertisement of the chocolate bar, the following multi-item scales referred directly to this online advertisement (see Fig. 2). In this way, the indicators of the first determinant consumers' beliefs about psychological mediators, the third determinant consumers' beliefs about persuasion coping goals and tactics, as well as the fourth and fifth determinant consumers' beliefs about the appropriateness of the marketers' persuasion tactic and consumers' beliefs about the effectiveness of the marketers' persuasion tactic were evaluated directly after participants had seen the advertisement. On the last two determinants (appropriateness and effectiveness), we presented the following note on the Fair-Trade label as persuasion tactic.

"Tactic: By using the Fair-Trade label on the chocolate bar, the chocolate bar marketer intends to increase the sales figures of the product and, therefore, his revenue. The primary goal of using the Fair-Trade label is not the support of cocoa farmers."

By presenting the definition, we aimed to ensure an equal perception and interpretation of the persuasion tactic by all participants. This definition was presented shortly before the end of our survey (see Fig. 2) to avoid any influence of the persuasion tactic definition on the respondents when answering the other indicators of the persuasion knowledge determinants. In the last step, we assessed our dependent variable beliefs about consumers' avoidance of the persuasion attempt. The third stage of our survey included questions on participants' socio-demographics, i.e., questions on gender and age as well as a question regarding a nutritional focus of participants' university studies.

\section{Measures}

Our section on the theoretical background of the PKM and the review article by Ham et al. (2015) indicate that there is no standard instrument for measuring persuasion knowledge. Therefore, scholars usually develop context-specific measurement scales or adapt existing scales to their research subject. We adopted this procedure and measured the persuasion knowledge determinants through multi-item scales. Wherever possible, we adapted measurement scales from previous PKM studies (see Appendix, Table 3). Since not all persuasion knowledge determinants were captured with multi-item scales in the literature so far, and some of the scales were not suitable for our research objective, we developed several multi-item scales on our own and modified existing multi-item scales. We used several indicators that represent different aspects and allow an evaluation of each persuasion knowledge determinant.

We measured the dependent variable beliefs about consumers' avoidance of the persuasion attempt using a self-developed measurement scale that reflected aspects of resistance to a product purchase and negative responses to the advertisement. However, only the indicators that were considered as reliable and valid in the later verification of the measurement models were maintained for the empirical analysis and therefore presented in Table 3 (Appendix) and in the results section. In our survey, all indicators were translated into German and were measured with a six-point 
approval scale from "I don't agree at all (1)" to "I totally agree (6)". We used an approval scale without a center to avoid response tendencies towards the middle. To avoid sequence effects, the indicators within the persuasion knowledge determinants were displayed randomly in our survey.

To examine the influence of the determinants of persuasion knowledge on the avoidance of the persuasion attempt, we used structural equation modeling. Structural equation modeling enables us to test our hypotheses about the hypothetical constructs which we derived in the previous section. Based on metric data, the missing normal distribution, and the formative measurement models, we used the partial least squares (PLS) approach for the parameter estimation of the structural equation model (Hair et al. 2014). For structural equation modeling, Chin (1998) recommends a sample size at least ten times larger than the number of indicators of the most complex formative construct. In line with this recommendation, the criterion of minimum sample size of our structural equation model is fulfilled.

Structural equation models consist of measurement models and a structural model. Measurement models show relationships between constructs, i.e., between the persuasion knowledge determinants and their indicators whereas the structural model shows the assumed relationships between the constructs. In measurement models, a distinction is made between reflectively and formatively measured models. A reflectively measured model means that the construct causes the measurement of the indicator variables. Thus, covariances between indicators are required. Indicators should be interchangeable and contain a similar topic. Formatively measured models are used when indicators cause the measurement of the construct. For the indicators, there is no need to contain similar topics and covariances between indicators are not required (Hair et al. 2014; Jarvis et al. 2003).

\section{Results}

\section{Quality criteria}

As a first step, we verify the quality criteria of the measurement models. Table 1 shows that the measures indicator reliability, convergent validity, internal consistency (composite reliability), Cronbach's alpha as well as the discriminant validity (see Appendix, Table 4) are satisfied for the reflectively measured construct beliefs about consumers' avoidance of the persuasion attempt.

Table 1 Results for reflectively measured models

\begin{tabular}{llllll}
\hline Construct & Indicators & $\begin{array}{l}\text { Indicator } \\
\text { reliability } \\
\text { loadings }\end{array}$ & $\begin{array}{l}\text { Convergent } \\
\text { validity } \\
\text { AVE } \\
(\geq 0.7)\end{array}$ & $\begin{array}{l}\text { Composite } \\
\text { reliability } \\
\mathrm{P}_{\mathrm{c}}\end{array}$ & $\begin{array}{l}\text { Cronbach's } \\
\text { alpha } \\
\alpha\end{array}$ \\
\hline $\begin{array}{r}\text { Beliefs about consumers' avoid- } \\
\text { ance of the persuasion attempt }\end{array}$ & {$[\mathrm{AV} 1]$} & 0.897 & 0.798 & 0.888 & 0.747 \\
\hline
\end{tabular}


Table 2 Results for formatively measured models

\begin{tabular}{|c|c|c|c|c|}
\hline Construct & Indicators & $\mathrm{VIF}(<5)$ & Weights $(>0.1)$ & $\begin{array}{l}\text { Loadings } \\
(>0.5)\end{array}$ \\
\hline \multirow{7}{*}{$\begin{array}{l}\text { (1) Consumers' beliefs about psycho- } \\
\text { logical mediators }\end{array}$} & [PM1] (R) & 1.178 & $0.202 * *$ & $0.489 * * *$ \\
\hline & [PM2] & 1.312 & $0.193 *$ & $0.591 * * *$ \\
\hline & [PM3] (R) & 1.062 & 0.090 & $0.246^{* * *}$ \\
\hline & [PM4] & 1.418 & $0.350 * *$ & $0.758 * * *$ \\
\hline & [PM5] & 1.205 & $0.388 * * *$ & $0.660 * * *$ \\
\hline & [PM6] & 1.036 & $0.126^{*}$ & $0.192 * *$ \\
\hline & [PM7] & 1.378 & $0.310 * * *$ & $0.709 * * *$ \\
\hline \multirow{4}{*}{$\begin{array}{l}\text { (2) Consumers' beliefs about market- } \\
\text { ers' persuasion goals and tactics }\end{array}$} & [GT1] & 1.012 & 0.117 & $0.214^{*}$ \\
\hline & [GT2] & 1.026 & $0.452 * * *$ & $0.500 * * *$ \\
\hline & [GT3] (R) & 1.013 & $0.760 * * *$ & $0.790 * * *$ \\
\hline & [GT4] & 1.033 & $0.326 * *$ & $0.456 * * *$ \\
\hline \multirow{2}{*}{$\begin{array}{l}\text { (3) Consumers' beliefs about persua- } \\
\text { sion coping goals and tactics }\end{array}$} & [CT1] (R) & 1.005 & $0.421 * * *$ & $0.482 * * *$ \\
\hline & {$[\mathrm{CT} 2]$} & 1.005 & $0.878 * * *$ & $0.908 * * *$ \\
\hline \multirow{2}{*}{$\begin{array}{l}\text { (4) Consumers' beliefs about the } \\
\text { appropriateness of the marketers' } \\
\text { persuasion tactic }\end{array}$} & [AP1] (R) & 1.010 & $0.681^{* * *}$ & $0.600 * * *$ \\
\hline & [AP2] (R) & 1.010 & $0.804^{* * *}$ & $0.735 * * *$ \\
\hline \multirow{4}{*}{$\begin{array}{l}\text { (5) Consumers' beliefs about the } \\
\text { effectiveness of the marketers' } \\
\text { persuasion tactic }\end{array}$} & {$[\mathrm{EF} 1]$} & 2.124 & 0.181 & $0.748 * * *$ \\
\hline & [EF2] & 2.015 & $0.390 * * *$ & $0.803 * * *$ \\
\hline & [EF3] (R) & 1.111 & $0.525 * * *$ & $0.627 * * *$ \\
\hline & [EF4] & 1.061 & $0.364 * *$ & $0.545^{* * *}$ \\
\hline
\end{tabular}

$(R)$ Reversed answers

$* p<0.1 ; * * p<0.05 ; * * * p<0.01$

In Table 2, the quality criteria of formatively measured models are evaluated. The variance inflation factor (VIF) of all indicators is less than five indicating that there are no critical levels of collinearity. The weights, which reflect the importance of the individual indicators for the corresponding construct, are $>0.1$ and significant except for indicators [PM3] (R), [GT1], and [EF1]. However, all of these indicators achieve significant loadings and are therefore kept in the model.

Next, the quality criteria of the structural model are analyzed. The VIF results of our structural model are less than five indicating that collinearity is not a problem (see Appendix, Table 5). According to Hair et al. (2014), the coefficient of determination $\left(R^{2}\right)$ value is a measure of the model's predictive accuracy and represents the combined effects of the five (exogenous) constructs on the dependent variable beliefs about consumers' avoidance of the persuasion attempt. Results show that in total, $21.8 \%$ of the variance in avoidance of the persuasion attempt is explained by the assigned constructs. The effect size $\left(f^{2}\right)$ reflects the influence of an exogenous construct on the dependent variable and differs in its extent (Hair et al. 2014). Threshold values for the $f^{2}$ of $0.02,0.15$, and 0.35 indicate whether the exogenous construct has a weak, moderate, or substantial influence on the dependent variable (Chin 1998). Results in Table 5 (Appendix) show that the effect sizes of the exogenous constructs are different. The exogenous determinants consumers' beliefs 
about psychological mediators, consumers' beliefs about the appropriateness of the marketers' persuasion tactic, and consumers' beliefs about the effectiveness of the marketers' persuasion tactic have at least a weak influence on the beliefs about consumers' avoidance of the persuasion attempt. For the determinants consumers' beliefs about marketers' persuasion goals and tactics and consumers' beliefs about persuasion coping goals and tactics, the $\mathrm{f}^{2}$ - values are below 0.02 , which indicates that there are no remarkable influences on the beliefs about consumers' avoidance of the persuasion attempt. The Stone-Geissers' $Q^{2}$ value, which measures the model's predictive relevance, is higher than zero $\left(Q^{2}: 0.154\right)$ (Hair et al. 2014). Thus, we conclude that our structural equation model on persuasion knowledge in food advertising represents aspects that cause avoidance. Furthermore, the Standardized Root Mean Square Residual (SRMR) is 0.054 and, therefore, less than 0.08 which indicates a good fit of the model according to Henseler et al. (2014). However, we have to mention that researchers should be cautious when using model fit indices in structural equation modelling with PLS as the criteria are not sufficiently validated and established thresholds do not exist which can lead to difficulties in evaluating results (Hair et al. 2017; SmartPLS GmbH 2021). For this reason, we refrain from interpreting further model fit indices.

\section{Hypotheses testing}

The hypotheses testing was carried out by using the software SmartPLS 3 (Ringle et al. 2015). In Fig. 4, we present the results of the structural equation model by indicating the path coefficients on the respective arrow. The height and significance of path coefficients are reported as results of hypotheses testing. We present the effect sizes of the path coefficients in bold if they are significant and thus support our hypotheses. Path coefficients can be interpreted like standard beta coefficients of an ordinary least squares regression and show the relationships between the respective persuasion knowledge determinant and the dependent variable beliefs about consumers' avoidance of the persuasion attempt. In general, the higher a path coefficient of a determinant, the higher the relative influence of this determinant on the dependent variable. To evaluate the significance of the path coefficients, we apply bootstrapping with 5,000 subsamples (Hair et al. 2014).

The results of hypotheses testing show that hypothesis $\mathrm{H} 1\left(-0.301^{* * *}\right)$ is supported meaning that in our study the positive evaluation of consumers' beliefs about psychological mediators in the advertisement has a significant negative influence on the beliefs about consumers' avoidance of the persuasion attempt. From this result, it can be deduced that a positive evaluation of psychological mediators in the chocolate bar advertisement is more likely leading to tolerance of this advertisement than on its avoidance. Hypothesis H2 $(-0.066)$ is not supported due to the negative sign and the lack of significance of the path coefficient. Thus, in our study the determinant consumers' beliefs about marketers' persuasion goals and tactics does not influence the beliefs about consumers' avoidance of the persuasion attempt. Hypothesis H3 $\left(0.107^{* *}\right)$ is supported meaning that more pronounced beliefs about consumers' persuasion coping goals and tactics leads to avoidance of the persuasion 


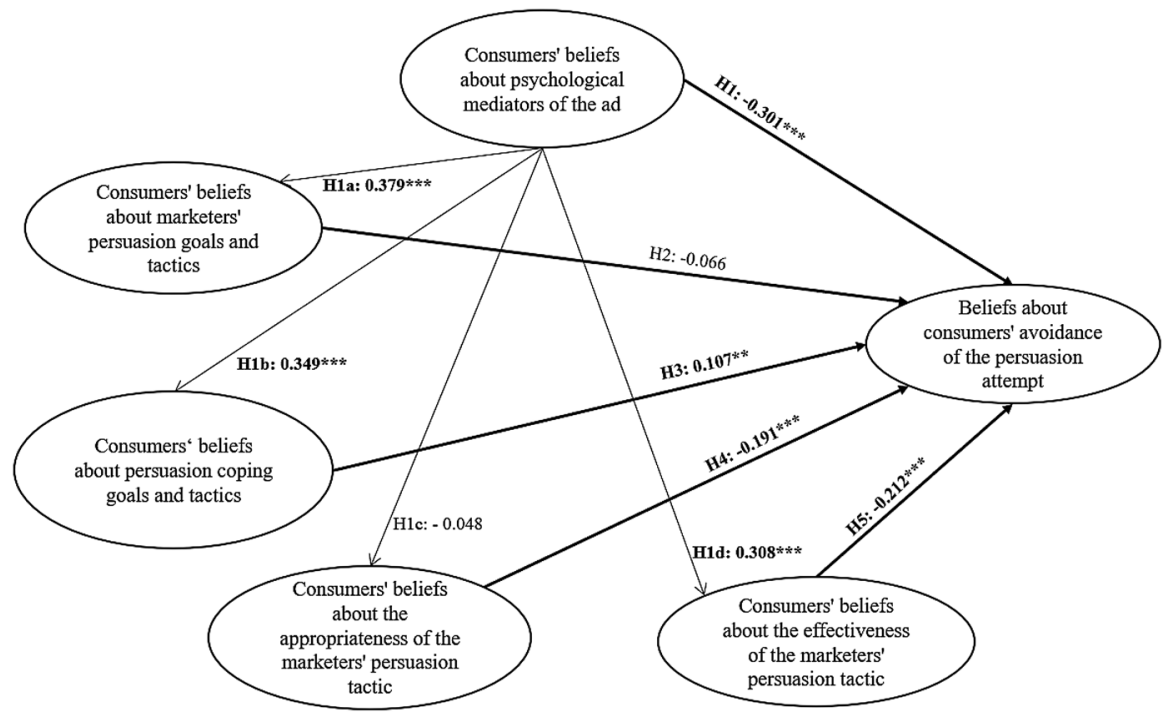

Fig. 4 Structural equation model and results of hypotheses testing. Note: $* p<0.1 ; * * p<0.05$; $* * * p<0.01$

attempt. Hypothesis H4 (- 0.191***) and hypothesis H5 (- 0.212***) are supported implying that consumers' beliefs about the effectiveness of the marketers' persuasion tactic and consumers' beliefs about the appropriateness of the marketers' persuasion tactic have a significant negative influence on the beliefs about consumers' avoidance of the persuasion attempt. Thus, participants in our study expect that the more effective and appropriate a persuasion tactic is evaluated by consumers, the less likely consumers will avoid it. Consequently, if the persuasion tactic is evaluated to be ineffective and inappropriate, the avoidance of the respective persuasion attempt will increase. The height of the path coefficients shows that the negative effect of evaluating the persuasion tactic effectiveness is greater than the negative effect of evaluating the persuasion tactic appropriateness on the avoidance. The greatest negative influence on the beliefs about consumers' avoidance of the persuasion attempt is identified for the determinant consumers' beliefs about psychological mediators. From this, we conclude that participants of our study expect the avoidance to be lower when consumers have higher beliefs about psychological mediators of the advertisement and when consumers evaluate the advertising tactic as appropriate and effective.

According to the PKM theory, the determinant consumers' beliefs about psychological mediators forms the basis of the remaining persuasion knowledge determinants. Thus, we test hypotheses H1a- H1d to examine if consumers' beliefs about psychological mediators affect the further determinants of persuasion knowledge. Results show that consumers' beliefs about psychological mediators have the greatest positive effect on consumers' beliefs about marketers' persuasion goals and tactics (H1a: $0.379^{* * *}$ ) followed by consumers' beliefs about persuasion coping goals and tactics ( $\left.\mathrm{H} 1 \mathrm{~b}: 0.349^{* * *}\right)$, and consumers' beliefs about the effectiveness of the 
marketers' persuasion tactic (H1d: $\left.0.308^{* * *}\right)$. The hypothesis on consumers' beliefs about the appropriateness of the marketers' persuasion tactic (H1c: -0.048) is not supported because there is no significant and a negative effect. In line with the PKM theory, our results indicate that the determinant consumers' beliefs about psychological mediators can be used as fundament for persuasion knowledge among food consumers.

In our structural equation analysis, the coefficient of determination $\left(R^{2}\right)$ shows that $21.8 \%$ of the variance of the beliefs about consumers' avoidance of the persuasion attempt is explained by the corresponding determinants. We conclude that this explanation of variance is plausible since the PKM also includes knowledge factors such as agent and topic knowledge whose impacts we do not examine in our analysis. Factors that could influence persuasion avoidance might include consumers' persuasion experience as well as the already mentioned agent and topic knowledge. The theory of consumer behavior also discusses that food consumers have product and brand loyalty and a different involvement in purchase decisions (Grunert 2006; Neumann 2009). We assume that there might also be an influence of these factors.

\section{Discussion and implications}

\section{Implications for food advertisers}

The design of food advertising messages is influenced by the habitual purchase behavior of food consumers. Using affective elements, advertisers try to increase the emotional involvement of consumers and thereby to influence consumers' purchase behavior in favor of their products (Neumann 2009). Therefore, advertising ideas must be both, original and appropriate (West et al. 2019). Referring to our study, it seems to be important to implement advertising tactics that are perceived as appropriate and effective. Our results show that the evaluation of the effectiveness and appropriateness of the persuasion tactic have a comparatively large impact on whether consumers avoid the chocolate bar advertisement or not. However, it should be noted that in this study the persuasion tactic is associated with the Fair-Trade label which is a quality label for social standards, such as fair working conditions and prohibition of child labor and discrimination (TransFair 2021). Since fair trade products involve a social judgement by consumers, it is possible that the results of this study are not applicable to persuasion tactics without such a label for social standards, and therefore transferring the results to food advertising in general is difficult. For example, Campbell et al. (2015) show that price increases justified by Fair-Trade labels are perceived as fair compared to when price increases are justified by profit maximization. In our study, the persuasion tactic is described as a tactic that primarily aims to increase the marketer's revenue instead of supporting cocoa farmers. However, the participants' perception of the tactic can also be predominantly determined by the fairness characteristics of the label rather than the marketer's intention. From the survey, we cannot infer how the participants perceived the described persuasion tactic and the label displayed in the advertisement. 
Future studies could examine this question, for example, within the framework of an experiment.

From this study, it can be concluded that to maximize food advertisers' revenues, persuasion tactics that are perceived as appropriate, fair, and effective by consumers should be implemented. Conversely, our results indicate that the use of inappropriate and unfair persuasion tactics can lead to a less favorable perception of products, brands, and advertisers by consumers. However, inappropriate persuasion tactics can not only be recognized through consumer perceptions but also through thirdparty disclosures which can negatively affect a whole branch of industry (Darke et al. 2008; Held et al. 2017). In addition to persuasion tactics in advertisements, Held et al. (2017) also recommend fair and effective persuasion tactics for retail sale strategies.

However, it can be questioned to what extent advertisers in Germany even use inappropriate advertisement tactics. In Germany, there are legal requirements and a voluntary code of conduct for food advertising that prohibit misleading and inadmissible advertising. The code of conduct for food advertising states that advertising activities must be recognizable for consumers. In addition, consumers can also contact the German Advertising Council if they consider advertising messages to be unacceptable (Lebensmittelverband Deutschland e.V. (Food Federation Germany) 2020).

Furthermore, it is expected that the appropriateness and fairness of advertising tactics will also gain relevance in personalized advertising messages (Malheiros et al. 2012). Due to digitalization, data on consumers' purchase behavior, i.e., behavior-related information are available and can be used by advertisers to develop and send their advertising messages to specific target groups. By using technologies such as algorithms and artificial intelligence, personalized advertising messages can be specifically targeted towards consumers in terms of time and topic ( $\mathrm{Li}$ 2019). Thus, personalized advertising messages result in a decision support for consumers that is adapted to their personal consumption patterns. Advertisers benefit from an increased advertising effect and can reduce scatter losses (Acquisti et al. 2016). However, too intense personalization of advertising messages could limit the sovereignty of food consumers and have a harassing effect. Concerning this, a representative population survey in Germany of the company PwC (2019) determines that online advertising is perceived as very or rather disturbing by $68 \%$ of the interviewees.

Another finding of our study is that a positive evaluation of consumers' beliefs about psychological mediators in the advertisement negatively influences advertisement avoidance. Thus, using psychological mediators, such as communicating emotions, a feeling of trust or creating a desire in an advertisement can lead to a positive coping behavior among consumers that, in the best case, results in a product purchase. At this point, however, we must note that in our study the determinant consumers' beliefs about psychological mediators cannot be considered equivalent to consumers' knowledge about psychological mediators. In our study, we capture the first determinant as the study participants' evaluation of consumers' beliefs about psychological mediators used in our chocolate bar advertisement. Thus, we do not directly assess consumers' knowledge about psychological mediators and its 
influence on advertisement avoidance which could affect consumers' coping behavior differently.

\section{Implications for consumer education}

In addition to recommendations for food advertisers, recommendations for food consumer education can be deduced. The fact that consumers' beliefs about persuasion coping goals and tactics have a significant positive but comparatively small impact on the beliefs about consumers' avoidance of the persuasion attempt leads to the question of whether there is an increasing need for consumer education regarding coping goals and tactics as well as an information provision on persuasive elements in advertising. We assume, if consumers have a higher level of beliefs about possible persuasion coping goals and tactics when dealing with advertising, they will be able to deal with persuasion attempts consciously and can cope with them more easily. For example, as described in our indicators, consumers could be made aware that they can use advertisements to form long-term opinions about marketers, products, and brands. Moreover, a provision and disclosure of persuasion-related information can make consumers more aware of marketers' persuasion intentions and tactics (Campbell et al. 2013). Regarding this, consumers' dealing with personalized advertising messages should also be considered.

In our study, we also find that a greater evaluation of consumers' beliefs of psychological mediators in food advertising messages leads to greater consumers' beliefs about marketers' persuasion goals and tactics (see Fig. 4, H1a) and to greater consumers' beliefs about persuasion coping goals and tactics (see Fig. 4, $\mathrm{H} 1 \mathrm{~b})$. Thus, we assume that educating consumers about the psychological effects caused by advertising can be relevant to their coping behavior. For example, consumers could be made aware that advertising tries to create a special mood among them and arouses emotions and trust. A provision of information about marketers' goals and tactics could be useful for consumers as well. Furthermore, in our analysis higher ratings of consumers' beliefs about psychological mediators in the advertisement lead to a more favorable evaluation of persuasion tactic effectiveness (see Fig. 4, H1d). Thus, we expect that consumers' education about psychological mediators may create awareness of persuasion tactics and then lead to a more conscious handling of advertisements, at least among some consumers.

\section{Conclusion, limitations, and outlook}

Our study presents how persuasion knowledge determinants can be examined in a food advertisement setting by using a structural equation modeling approach. Our results show that persuasion knowledge determinants influence consumers' dealing with persuasion attempts since four out of five of our main hypotheses are maintained. The determinants consumers' beliefs about psychological mediators, consumers' beliefs about the appropriateness of the persuasion tactic, and consumers' beliefs about the effectiveness of the persuasion tactic negatively influence the 
beliefs about consumers' avoidance of the persuasion attempt. The determinant consumers' beliefs about persuasion coping goals and tactics positively influences beliefs about consumers' avoidance of the persuasion attempt. We find no significant effect for consumers' beliefs about marketers' persuasion goals and tactics.

However, since persuasion knowledge correlates with age and education (e.g., Boush et al. 1994; Kirmani and Campbell 2004), it should be noted that only students participated in our study. With an average age of 24.23 years, our participants are comparatively young and well educated. Therefore, the results of our study cannot be transferred to the entire population in Germany. Furthermore, the descriptive statistics on participants' age show that the median is 23.00 years and 23.71 years for the $5 \%$ trimmed mean. Using a boxplot, 19 outliers (age $\geq 34$ years) are identified. Based on the descriptive statistics on age, we test for statistically significant differences in the mean values between the groups (group 1: age $\geq 34$, group 2: age $\leq 33$ ) for each indicator using Mann-Whitney $U$ tests. The results show that there are no significant differences in mean values for almost all indicators $(p>0.05)$. The only exception is the indicator [GT2] for which a $p$ value of 0.042 is determined. Due to the large number of non-significant differences in respondents' answers between the two groups, we conclude that there are no age-related differences in this model. Therefore, we decided against recalculating the SEM for different age groups. In addition, nearly half of the respondents (42.86\%) deal with nutrition topics during their university studies. Thus, we cannot exclude that participants in our study are better educated in persuasive food advertising than the average consumer which could lead to biased results. An analysis with a larger target group consisting not only of students and a larger share of male participants could provide further insights for different consumer groups. In addition to the age and education of the study participants, a further limitation of our study is that the draw of chocolate bar surprise packages mainly motivated students with a preference for chocolate to participate. We assume that participants with a self-identified interest in sweets could be more involved in the topic than the average student. It is possible that a survey with another kind of incentive would lead to different results and attract other students to participate.

A further limitation of our study relates to our measurement scales. We dropped some indicators because they did not meet the quality criteria of structural equation modeling. Thus, some of our measurement scales might not fully capture the respective determinant. For example, for our third determinant consumers' beliefs about persuasion coping goals and tactics, we removed indicators about understanding and dealing with the chocolate bar advertisement due to unsatisfactory quality criteria. The same applied to the second determinant consumers' beliefs about marketers' persuasion goals and tactics. We removed persuasion tactic indicators about words, colors, pictures, and sounds in advertising.

An additional uncontrolled factor is the possibility of a response bias due to social desirability. Particularly in surveys on process attributes of food, people tend to provide socially desirable answers (Grohs et al. 2009; Piper and Kühl 2020). As explained in the second section, to avoid response bias due to social desirability, our survey does not directly capture participants' knowledge of each individual persuasion knowledge determinant. Instead, we asked respondents about their expectation 
of how consumers interact with the advertisement of the chocolate bar. In addition, the instructions of the survey informed respondents that there are no right and wrong answers and that the information provided is handled confidentially. However, a response bias due to social desirability cannot be completely excluded. Future studies could test for biased responses due to social desirability by implementing the control scale SEMAF07. The scale was developed by Grohs et al. (2009) (in German) to test for socially desirable response behavior in consumer behavior surveys. Using this scale, the extent of response bias can be determined and, therefore, participants with a strong bias can be eliminated for the analysis or the bias effect can be weighted (Mummendey and Grau 2014). Moreover, a future analysis could directly address participants' beliefs which could, however, lead to response bias among them.

Furthermore, we would like to mention the incomplete representation of the PKM in our study. Since our survey participants have no purchase experience with the product, the development of persuasion-independent product and agent knowledge is prevented. In our study, agent and topic knowledge would only result from the advertisement. Therefore, we deliberately refrain from evaluating the influence of agent and topic knowledge on the avoidance of the advertisement. However, to examine the impact of agent and topic knowledge on the avoidance of a persuasion attempt, a two-stage analysis would be conceivable. Survey participants can, for instance, receive information about the fictitious product and the fictitious marketer a few days before answering the actual survey. Thus, in the second survey, an advertising-independent product and agent knowledge can be identified and the effects on avoidance of advertising attempts can be examined. In addition, a study with a real product and marketer could provide further insights. By using existing brands and products, the influence of trust aspects and company reputation could also be investigated. This is in line with Tutaj and van Reijmersdal (2012) who conclude from their experimental study on the effects of online advertising and persuasion knowledge on audience reactions that brand awareness and attitude should also be examined in further analysis.

Finally, we present a short outlook on the positive handling of persuasion attempts. The initiators of the PKM point out that consumers do not always resist persuasion attempts since the PKM only suggests that with an increasing persuasion knowledge consumers can better control persuasion attempts (Campbell and Kirmani 2008; Friestad and Wright 1994; Ham et al. 2015). For example, Isaac and Grayson (2017) state that a strong persuasion knowledge can also lead to greater credibility and thus to acceptance of persuasion attempts. Consumers consciously perceive advertising messages with credible advertising tactics as beneficial. With emerging advertising approaches like personalized advertising, it is possible that consumers will even evaluate advertising that is tailored to their own purchase wishes and needs as positive or even profitable. Regarding this, a representative survey for Germany conducted by PwC (2019) finds that about one third of the interviewees like displayed advertising that corresponds to their own interests. However, Ham (2017) examines how consumers cope with online behavioral advertising and shows that participants use persuasion knowledge for their coping behavior of avoidance which is also shown in existing research on persuasion knowledge and covert marketing 
strategies (e.g., Boerman et al. 2018; Campbell et al. 2013; Wei et al. 2008; Xie et al. 2015). Lastly, it should be noted that persuasion attempts are not limited to advertising in food settings. An implementation of the PKM on a point of sale conversation scenario is also possible. However, it should be kept in mind that sales situations in which a marketer persuades a consumer are rather rare in food settings. Nevertheless, persuasion attempts are possible with promotion and tasting actions of food.

Supplementary Information The online version contains supplementary material available at https://doi. org/10.1007/s43546-021-00108-y.

Acknowledgements We thank Merindah Loessl and Janis Cloos for helpful feedback and comments.

Author contributions All authors contributed to the study conception and design. SM performed the material preparation, data collection as well as the data analysis and wrote the first draft of the manuscript. Both authors commented on previous versions of the manuscript, read and approved the final manuscript.

Funding Open Access funding enabled and organized by Projekt DEAL. No funding was received for conducting this study.

Availability of data and material Data and material are available upon request.

\section{Declarations}

Conflict of interest The authors have no conflicts of interest to declare that are relevant to the content of this article.

Open Access This article is licensed under a Creative Commons Attribution 4.0 International License, which permits use, sharing, adaptation, distribution and reproduction in any medium or format, as long as you give appropriate credit to the original author(s) and the source, provide a link to the Creative Commons licence, and indicate if changes were made. The images or other third party material in this article are included in the article's Creative Commons licence, unless indicated otherwise in a credit line to the material. If material is not included in the article's Creative Commons licence and your intended use is not permitted by statutory regulation or exceeds the permitted use, you will need to obtain permission directly from the copyright holder. To view a copy of this licence, visit http://creativecommons.org/licen ses/by/4.0/.

\section{References}

Acquisti A, Taylor C, Wagman L (2016) The economics of privacy. J Econ Lit 54(2):442-492. https://doi. org/10.1257/jel.54.2.442

Ahluwalia R, Burnkrant RE (2004) Answering questions about questions: a persuasion knowledge perspective for understanding the effects of rhetorical questions. J Consum Res 31(1):26-42. https:// doi.org/10.1086/383421

Balzás K, Bene Á, Hidegkuti I (2017) Vulnerable older consumers: new persuasion knowledge achievement measure. Int J Consum Stud 41(6):706-713. https://doi.org/10.1111/ijcs.12383

Bearden WO, Hardesty DM, Rose RL (2001) Consumer self-confidence: refinements in conceptualization and measurement. J Consum Res 28(1):121-134. https://doi.org/10.1086/321951

Berkovsky S, Freyne J, Oinas-Kukkonen H (2012) Influencing individually: fusing personalization and persuasion. ACM Trans Interact Intell Syst 2(2):1-8. https://doi.org/10.1145/2209310.2209312 
Boerman SC, van Reijmersdal EA, Rozendaal E, Dima AL (2018) Development of the persuasion knowledge scales of sponsored content (PKS-SC). Int J Advert 37(5):671-697. https://doi.org/10.1080/ 02650487.2018.1470485

Boush DM, Friestad M, Rose GM (1994) Adolescent skepticism toward TV advertising and knowledge of advertiser tactics. J Consum Res 21(1):165-175. https://doi.org/10.1086/209390

Campbell MC (1995) When attention-getting advertising tactics elicit consumer inferences of manipulative intent: the importance of balancing benefits and investments. J Consum Psychol 4(3):225-254. https://doi.org/10.1207/s15327663jcp0403_02

Campbell MC, Kirmani A (2000) Consumers' use of persuasion knowledge: the effects of accessibility and cognitive capacity on perceptions of an influence agent. J Consum Res 27(1):69-83. https://doi. org/10.1086/314309

Campbell MC, Kirmani A (2008) I know what you're doing and why you're doing it: the use of persuasion knowledge model in consumer research. In: Haugtvedt C, Herr P, Kardes F (eds) Handbook of Consumer Psychology. Erlbaum, New York, pp 549-572

Campbell MC, Mohr GS, Verlegh PWJ (2013) Can disclosure lead consumers to resist covert persuasion? The important roles of disclosure timing and type of response. J Consum Psychol 23(4):483-495. https://doi.org/10.1016/j.jcps.2012.10.012

Campbell CL, Heinrich D, Schoenmüller V (2015) Consumers' reaction to fair trade motivated price increases. J Retail Consum Serv 24:79-84. https://doi.org/10.1016/j.jretconser.2015.02.005

Celsi M, Gilly M (2009) Employees as internal audience: How advertising affects employees' customer focus. J Acad Mark Sci 38(4):520-529. https://doi.org/10.1007/s11747-009-0173-X

Chin WW (1998) The partial least squares approach to structural equation modeling. Modern methods for business research. In: Marcoulides GA (ed) Modern methods for business research. Erlbaum, New York, pp 295-336

Darke PR, Ashworth L, Ritchie RTB (2008) Damage from corrective advertising: causes and cures. J Mark 72(6):81-97. https://doi.org/10.1509/jmkg.72.6.081

Davison WP (1983) The third person effect in communication. Public Opin Q 47(1):1-15. https://doi.org/ $10.1086 / 268763$

Eisend M (2015) Persuasion knowledge and third-person perceptions in advertising: the moderating effect of regulatory competence. Int J Advert 34(1):54-69. https://doi.org/10.1080/02650487.2014.993792

Felser G (2015) Werbe- und Konsumentenpsychologie (Advertising and consumer psychology), 4th edn. Springer, Berlin

Forehand MR, Grier S (2003) When is honesty the best policy? The effect of stated company intent on consumer skepticism. J Consum Psychol 13(2):349-356. https://doi.org/10.1207/S15327663J CP1303_15

Fransen ML, Verlegh PWJ, Kirmani A, Smit EG (2015) A typology of consumer strategies for resisting advertising, and a review of mechanisms for countering them. Int J Advert 34(1):6-16. https://doi. org/10.1080/02650487.2014.995284

Friestad M, Wright P (1994) The persuasion knowledge model: how people cope with persuasion attempts. J Consum Res 21(1):1-31. https://doi.org/10.1086/209380

Friestad M, Wright P (1995) Persuasion knowledge: lay people's and researchers' beliefs about the psychology of advertising. J Consum Res 22(1):62-74. https://doi.org/10.1086/209435

Grohs R, Ebster C, Kummer C (2009) „An meinen Fähigkeiten als Liebhaber habe ich schon gezweifelt" Die Messung sozial erwünschten Antwortverhaltens ("I have already doubted my abilities as a lover" Measuring socially desirable response behavior). Marketing 31(2):87-100

Grunert KG (2006) Marketing parameters and their influence on consumer food choice. In: Shepherd R, Raats M (eds) The psychology of food choice, 3rd edn. CABI, Wallinford, pp 161-177

Gunter B (2016) Food advertising. Nature, impact and regulation. Palgrave Macmillan, London

Hair JF, Hult GTM, Ringle GM, Sarstedt M (2014) A primer on partial least squares structural equation modeling (PLS-SEM). Sage Publications, Los Angeles

Hair JF, Hollingsworth CL, Randolph AB, Chong AYL (2017) An updated and expanded assessment of PLS-SEM in information systems research. Ind Manag Data Syst 117(3):442-458. https://doi.org/ 10.1108/IMDS-04-2016-0130

Ham CD (2017) Exploring how consumers cope with online behavioral advertising. Int J Advert 36(4):632-658. https://doi.org/10.1080/02650487.2016.1239878

Ham CD, Nelson MR, Das S (2015) How to measure persuasion knowledge. Int J Advert 34(1):17-53. https://doi.org/10.1080/02650487.2014.994730 
Ham CD, Yoon G, Nelson MR (2016) The interplay of persuasion inference and flow experience in an entertaining food advergame. J Consum Behav 15(3):239-250. https://doi.org/10.1002/cb.1564

Held J, Stieler M, Germelmann CC, Ashworth L (2017) When brand representatives act as sales associates: Mechanism and effects of native selling and its disclosure. Market ZFP 39(1):44-57. https:// doi.org/10.15358/0344-1369-2017-1

Henseler J, Dijkstra TK, Sarstedt M, Ringle CM, Diamantopoulos A, Straub DW, Ketchen DJ, Hair JF, Hult TM, Calantone RJ (2014) Common beliefs and reality about PLS: comments on Rönkkö and Evermann (2013). Organ Res Methods 17(2):182-209. https://doi.org/10.1177/1094428114526928

Isaac MS, Grayson K (2017) Beyond skepticism: Can accessing persuasion knowledge bolster credibility? J Consum Res 43(6):895-912. https://doi.org/10.1093/jcr/ucw063

Jarvis C, MacKenzie S, Podsakoff P (2003) A critical review of construct indicators and measurement model misspecification in marketing and consumer research. J Consum Res 30(2):199-218. https:// doi.org/10.1086/376806

Kaptein M, De Ruyter B, Markopoulos P, Aarts E (2012) Adaptive persuasive systems: a study of tailored persuasive text messages to reduce snacking. ACM Trans Interact Intell Syst 2(2):1-25. https://doi. org/10.1145/2209310.2209313

Kirmani A, Campbell MC (2004) Goal seeker and persuasion sentry. How consumer targets respond to interpersonal marketing persuasion. J Consum Res 31(3):573-582. https://doi.org/10.1086/425092

Lebensmittelverband Deutschland e.V. (2020) Werbung für Lebensmittel (Advertising for food). https:// www.bll.de/de/lebensmittel/werbung. Accessed 09 Oct 2019

Li H (2019) Special section introduction: artificial intelligence and advertising. J Advert 48(4):333-337. https://doi.org/10.1080/00913367.2019.1654947

Malheiros M, Jennett C, Patel S, Brostoff S, Sasse MA (2012) Too close for comfort: A study of the effectiveness and acceptability of rich-media personalized advertising. Proc SIGCHI Conf Hum Factors Comput Syst. https://doi.org/10.1145/2207676.2207758

Matthes J, Naderer B (2016) Product placement disclosures: exploring the moderating effect of placement frequency on brand responses via persuasion knowledge. Int J Advert 35(2):185-199. https:// doi.org/10.1080/02650487.2015.1071947

Mummendey HD, Grau I (2014) Die Fragebogen-Methode. Grundlagen und Anwendung in Persönlichkeits-, Einstellungs- und Selbstkonzeptforschung (The questionnaire method. Fundamentals and application in personality, attitude, and self-concept research), 6th edn. Hogrefe, Göttingen

Naderer B, Binder A, Matthes J, Mayrhofer M (2020) Healthy, sweet, brightly colored, and full of vitamins: cognitive and affective persuasive cues of food placements and children's healthy eating behavior. Int J Advert 39(7):1012-1030. https://doi.org/10.1080/02650487.2020.1735140

Neumann R (2009) Die Involvementtheorie und ihre Bedeutung für das Lebensmittelmarketing (The involvement theory and its importance for the food marketing). Europäischer Hochschulverlag, Bremen

Nielsen and Media Impact (2018) Werbeausgaben für Süßwaren in Deutschland bis 2017. https://de.stati sta.com/statistik/daten/studie/197004/umfrage/werbeausgaben-fuer-schokolade-und-zuckerwarenin-deutschland-seit-2000/. Accessed 01 June 2020

Nielsen (2013) Werbespendings der Lebensmittelwirtschaft nach Mediengattungen im Jahr 2013. https:// de.statista.com/statistik/daten/studie/322092/umfrage/werbespendings-der-lebensmittelwirtschaftnach-mediengattungen/. Accessed 18 Nov 2020

Piper A, Kühl R (2020) Verzerrte Studienergebnisse als Grundlage für politische Entscheidungen? Eine Analyse am Beispiel des Nutztierwohls (Biased survey results as basis of political decision making: an analysis using the example of farm animal welfare). Ger J Agric Econ 69(1):64-79

PricewaterhouseCoopers (PwC) (2019) Personalisierte Werbung und E-Privacy 2019 (Personalized advertising and e-privacy 2019). https://www.pwc.de/de/pressemitteilungen/2019/personalisierteonline-werbung-erreicht-die-nutzer.html. Accessed 04 Sep 2020

Ringle CM, Wende S, Becker JM (2015) "SmartPLS 3“ Boenningstedt: SmartPLS GmbH. http://www. smartpls.com. Accessed 06 Apr 2020

Schweiger G, Schrattenecker G (2001) Werbung eine einführung advertising. An introduction. Lucius und Lucius, Stuttgart

SmartPLS GmbH (2021) Model fit. Note of caution. Available via https://www.smartpls.com/documentat ion/algorithms-and-techniques/model-fit. Accessed 08 Apr 2021

Tarabashkina L, Quester P, Crouch R (2016) Food advertising, children's food choices and obesity: Interplay of cognitive defences and product evaluation: an experimental study. Int J Obes 40(4):581-586. https://doi.org/10.1038/ijo.2015.234 
TransFair (2021) Fairtrade-standards. https://www.fairtrade-deutschland.de/was-ist-fairtrade/fairtradestandards. Accessed 26 Mar 2021

Tutaj K, van Reijmersdal EA (2012) Effects of online advertising format and persuasion knowledge on audience reactions. J Mark Commun 18(1):5-18. https://doi.org/10.1080/13527266.2011.620765

Valant J (2015) Consumer protection in the EU: Policy overview. European Union: European Parliamentary Research Service. http://aei.pitt.edu/96092/1/consumer.1.pdf. Accessed 07 Apr 2020

Verlegh PWJ, Fransen ML, Kirmani A (2015) Persuasion in advertising: when does it work, and when does it not? Int J Advert 34(1):3-5. https://doi.org/10.1080/02650487.2014.994732

Waiguny MKJ, Nelson MR, Terlutter R (2014) The relationship of persuasion knowledge, identification of commercial intent and persuasion outcomes in advergames: the role of media context and presence. J Consum Policy 37(2):257-277. https://doi.org/10.1007/s10603-013-9227-z

Wei ML, Fischer E, Main KJ (2008) An examination of the effects of activating persuasion knowledge on consumer response to brands engaging in covert marketing. J Public Policy Mark 27(1):34-44. https://doi.org/10.1509/jppm.27.1.34

West D, Koslow S, Kilgour M (2019) Future directions for advertising creativity research. J Advert 48(1):102-114. https://doi.org/10.1080/00913367.2019.1585307

Xie GX, Johnson JMQ (2015) Examining the third-person effect of baseline omission in numerical comparison: the role of consumer persuasion knowledge. Psychol Mark 32(4):438-449. https://doi.org/ 10.1002/mar.20790

Xie GX, Boush DM, Liu RR (2015) Tactical deception in covert selling: a persuasion knowledge perspective. J Mark Commun 21(3):224-240. https://doi.org/10.1080/13527266.2012.754369

Yoo CY (2009) The effects of persuasion knowledge on click-through of keyword search ads: moderating role of search task and perceived fairness. Journal Mass Commun Q 86(2):401-418. https://doi.org/ $10.1177 / 107769900908600209$ 